\title{
Blind prediction of FRP repairs for multiaxial fatigue cracks on Hydraulic Steel Structures
}

\author{
Guillermo Alberto Riveros ${ }^{1}$ and Christine Michelle Lozano ${ }^{1}$ \\ ${ }^{1}$ U.S. Army Engineer Research and Development Center, 3909 Halls Ferry Rd. Vicksburg, MS 39056
}

\begin{abstract}
Currently, over $80 \%$ of the navigation steel structures (NSS) within the United States' inland waterway system have reached or exceeded their useful design life. Age has caused deterioration of the design boundary conditions (e.g. diagonal relaxation and quoin block deterioration) leading to overloads and causing multi-axial fatigue cracking. Furthermore, corrosion and deterioration of the protective system accelerate the fatigue crack growth rate. This paper presents numerical experiments to evaluate the viability of fiber reinforce polymer (FRP) retrofit methods as an alternative to repair mix-mode fatigue cracking. The numerical experiments use a combination of tension, shear, and bending forces to develop different cracking patterns. Afterward, an analysis is conducted to demonstrate the effectiveness of the repair techniques on the defined problem. The need for a retrofit method is first motivated by the lack of effective and easily implemented retrofit techniques for underwater structures when mix-mode fatigue cracks are present. Extended finite element (XFEM), with Paris' Law and non-linear bond-slip behaviour of the adhesive, calibrates the crack propagation and strains surrounding the crack tip. The research then focuses on the discussion of the parametric analyses of large steel plate subjected to a combination of tension, shear and bending loads with and without CFRP repairs.
\end{abstract}

\section{Introduction}

The U.S. Army Corps of Engineers (USACE) operates and maintains 236 lock chambers at 191 lock sites on 41 waterways throughout the United States. Locks enable the flow of billions of dollars of commerce and support efforts for flood control [1]. Commercial barges lashed together as tows, with each barge capable of holding1400-1800 tons of cargo, utilize the U.S.'s extensive waterway network. A single tow of 15 barges carries the freight cargo equivalent of 870 tractor-trailer trucks creating a low-cost and fuelefficient mode of freight [2]. Proper maintenance of the locks and early detection of damage is crucial in maintaining the integrity and continuous operation of the waterways. However, due to shrinking budgets, adequate funding often not available to apply traditional scheduled maintenance and visual inspection [1]. To maintain the waterways at their current operational level and keep delays from growing beyond their current state a large investment is required [3]. 
The average age of navigation locks is over 60 years, and therefore experiencing deterioration of NSS elements caused by the loss of protective systems, corrosion, fatigue, impact, and overloads overtime [4-6] which have led to the discovery of multiaxial fatigue cracks (Fig. 2). A deterioration analysis conducted by [7] on horizontally framed miter gates (most commonly used gate) (Fig. 1) demonstrated that deterioration in the quoin block (Fig. 2) could drastically affect the state of stresses on the elements transferring loads to the pintle and the pintle connection. If the deterioration is severe, the stresses can reach levels of stresses large enough to induce cracking. Additionally, the lack of diagonal prestressing that provides torsional stiffness to the structural system will generate high levels of shear stresses in the pintle region, causing mix-mode loading and subsequent fatigue cracking as seen in Fig. 1. Furthermore, corrosion and deterioration of the NSS's protective system accelerate the fatigue crack growth rate creating accelerated mixed mode cracking large enough to threaten the integrity of the structure [8-9].
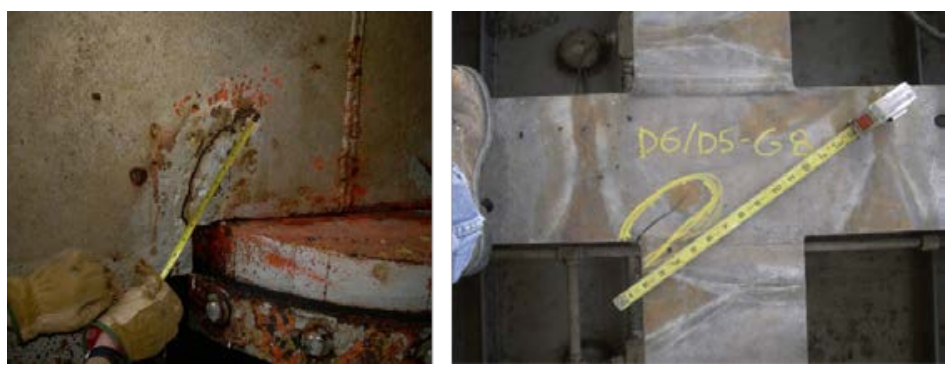

Fig. 1 Fatigue cracking in pintle region

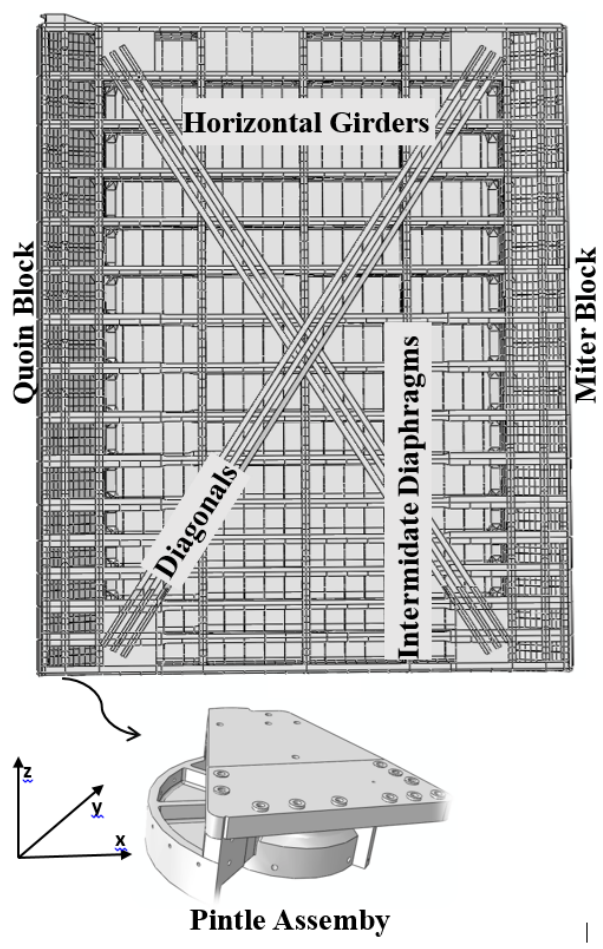

Fig. 2 Horizontally framed miter gate (downstream view) 
Current fatigue crack repair methods, guidelines, and provisions used for NSS were primarily adopted from the bridge engineering industry [10-11], but have proven ineffective. These methods are ineffective due to excessive corrosion and deterioration conditions as well as differences in operation and loading conditions. Additionally, most fatigue details and S-N curves developed by the American Association of State Highways and Transportation Officials (AASHTO) for steel bridges are predominantly subjected to Mode-I loading and cracking. Finally, the cost and time associated with the implementation of conventional repair methods are significant.

This article presents numerical experiments to evaluate the viability of fiber reinforced polymer (FRP) retrofit methods as an alternative to repair mix-mode fatigue cracking. The numerical experiments use a combination of tension, shear, and bending forces to develop different cracking patterns. Afterward, an analysis is conducted to demonstrate the effectiveness of the repair techniques on the defined problem. The need for a retrofit method is first motivated by the lack of effective and easily implemented retrofit techniques for underwater structures when mix-mode fatigue cracks are present.

\section{Literature Review}

Various studies have been carried out to assess the use of FRP for the rehabilitation of the increasingly aging and deteriorated civil structures and infrastructure systems in the US. Typically, deterioration manifests itself in terms of fatigue cracking or corrosion cracking. Most previously conducted studies were aimed at investigating the use of FRP for flexure and shear retrofitting of concrete structures [12-15]. The studies highlighted the significant potential of such an application as demonstrated by the numerous field implementations of FRP repair of concrete structures. Less research has been conducted on the use of FRP in strengthening metallic structures with most studies geared towards flexure retrofitting of aluminum panels in aviation [10]. Therefore, it is not surprising that the field implementation of FRP composites for retrofitting steel structures is scarce. In general, research efforts on retrofitting steel elements has examined the following areas: (1) repair of naturally deteriorated steel girders, (2) repair of an artificially notched girder or steel plates to simulate fatigue cracks, (3) strengthening an intact section to increase the girder stiffness and flexure capacity, and (4) increasing the composite action between the steel girder and concrete deck in bridge application. Very few studies have been conducted on fatigue crack propagation in CFRP-repaired large specimens representing real structural members [16-17].

\section{Model Overview and Numerical Experiments}

In this numerical study, a $1 \mathrm{~m}$ x $1 \mathrm{~m}$ x $9.5 \mathrm{~mm}$ rectangular steel plate with a $10 \mathrm{~cm}$ central crack was simulated under tension and shear loading with and without carbon fiber reinforced polymer (CFRP) patches.

Fig. 3 shows the finite element mesh used for the analysis with and without repairs. The main purpose of the models was to evaluate the state of stresses and mix mode crack growth rate on unrepaired and double-sided repaired (DSF) plates with CFRP.

Two numerical experiments with modified load boundary conditions were conducted (Fig. 3) to gain an understanding of the mixed mode behaviour. The plates were restrained at the bottom on the $\mathrm{X}, \mathrm{Y}$, and $\mathrm{Z}$ directions as well as on the side in the $\mathrm{X}$. A cyclic pressure was applied on the side $(1 / 4 \mathrm{H})$. Case 1 had an applied shear load of $110 \mathrm{Mpa}$ and no tensile load. Case 2 had a shear load of $110 \mathrm{Mpa}$, applied on the side, combined with a tensile load of $55 \mathrm{Mpa}$, applied at the top. To understand the contribution of each load 
condition the tensile and shear loads were applied at different time steps. Table 1 shows the load boundary conditions used on these numerical experiments. The material properties of the plates, CFRP, and adhesives are shown in Table 2.

Table 1. Cases with applied forces

\begin{tabular}{|c|c|c|}
\hline Case & $\begin{array}{c}\text { Shear } \\
\text { Magnitude } \\
\text { (Mpa) }\end{array}$ & $\begin{array}{c}\text { Tension } \\
\text { Magnitude } \\
\text { (Mpa) }\end{array}$ \\
\hline 1 & 110 & 0 \\
\hline 2 & 110 & 55 \\
\hline
\end{tabular}

Table 2. Material properties used in the finite element model

\begin{tabular}{|c|c|c|c|}
\hline $\begin{array}{c}\text { Material } \\
\text { Property }\end{array}$ & Steel & CFRP & Adhesive \\
\hline $\begin{array}{c}\text { Mass density } \\
\text { (kg/m3) }\end{array}$ & 7800 & 1740 & 1100 \\
\hline $\begin{array}{c}\text { Young's } \\
\text { Modulus } \\
\text { (Gpa) }\end{array}$ & 207 & 140 & 3.2 \\
\hline $\begin{array}{c}\text { Poisson's } \\
\text { Ratio }\end{array}$ & 0.3 & 0.4 & 0.4 \\
\hline
\end{tabular}

The finite element model was performed using the commercial software Abaqus 6.14 [18]. The plate specimen without CFRP repairs consists of a total of 33,360 C3D8R elements with a total number of 51,375 nodes. The repaired specimen had an additional 43,472 SC8R elements with 67,392 nodes. Extended finite element modelling (XFEM) was used to accomplish a logarithmic cyclic analysis (Paris' Law) with a C and m of 1.91e-04 and 1.16 respectively, and a $\mathrm{G}_{\mathrm{I}}$ and $\mathrm{G}_{\mathrm{II}}$ of 204 and 51 Mpa-m respectively.
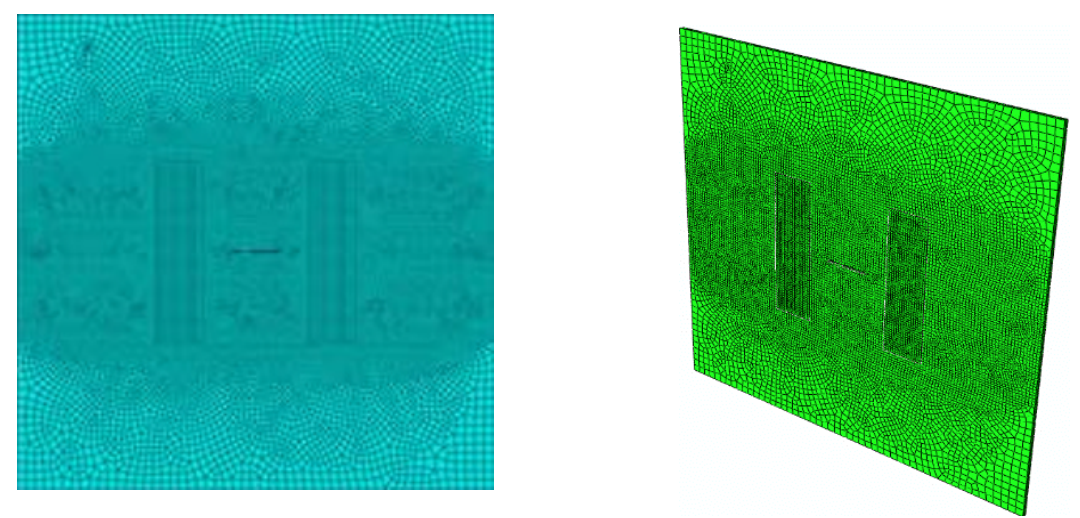

Fig. 3. XFEM finite element mesh with and without CFRP repairs. 


\section{Model Validation}

Authentication efforts focused on a general model approach [19] and the experiments described in [20]. The numerical experiments were analysed using identical methods and have been authenticated with experimental data; a discussion of the data and numerical methods are in [19-20]. The verification experiments were executed under Mode I loading with the CFRP application as in the laboratory experiments. The results of the numerical verification of the experiments conducted to verify the CFRP and adhesive interaction are presented in Fig. 4. The numerical validation utilized XFEM for the propagation and growth of the crack. The adhesive to steel contact bond was modelled with a cohesivedamage interaction and the CFRP to adhesive contact was modelled as a tied constraint. Fig. 4 also shows the validation of the experiments without repairs against the numerical model and the analytical model using the Paris' Law [21-22]

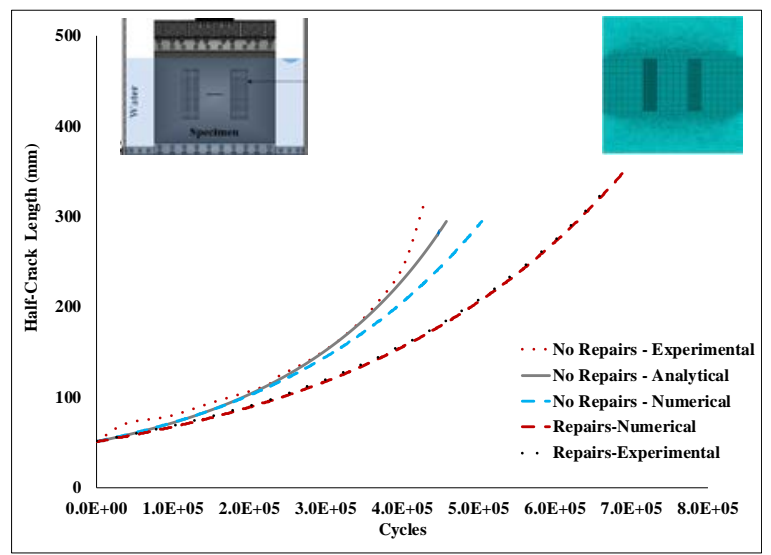

Fig. 4. Mode I numerical model validation

\section{Results}

\subsection{General observations of the crack patterns}

Fig. 5 shows the simulated shear crack, with and without repairs, induced by the loading condition of Case 1. On the model without repairs, the left side of the crack began propagating before the right side. This is attributed to the bending stresses developed by the transverse load that generates tensile stresses on the left side of the original crack. The left and right side grow at an angle of $52^{\circ}$ and $56^{\circ}$ respectively. The growth angle indicates the development of high shear stresses, due to the transverse load, in comparison to the normal stresses established by the bending stresses. The crack growth, for the repaired Case 1 model, begins similarly to the non-repaired case with initial angles of $52^{\circ}$ and $55^{\circ}$, respectively. Once the left crack begins to propagate under the CFRP, the crack growth's angle drops to $47^{\circ}$. The angle reduction, provided by the CFRP, indicates the improvement unidirectional FRP provides with regards to the crack pattern.

The shear crack growth for Case 2 with and without repairs is shown in Fig. 6. Case 2's crack pattern were influended by a combination of the applied pure tension, the shear stresses from the applied transverse load, and bending stresses developed by the transverse load. The combination of tensile and bending stresses caused the principal angle to drop by 
$45 \%$ from Case 1 . The repairs caused the left side crack to remain in shear until reaching the FRP repairs. After reaching the FRP repairs the left side crack turned and stayed in mode I dominated crack growth with a principal angle of $27^{\circ}$. On the left side, the crack turns $80^{\circ}$ before reaching the CFRP patch. This can be attributed to the combination of bending compressive stresses generated by the transverse load and the CFRP patch.

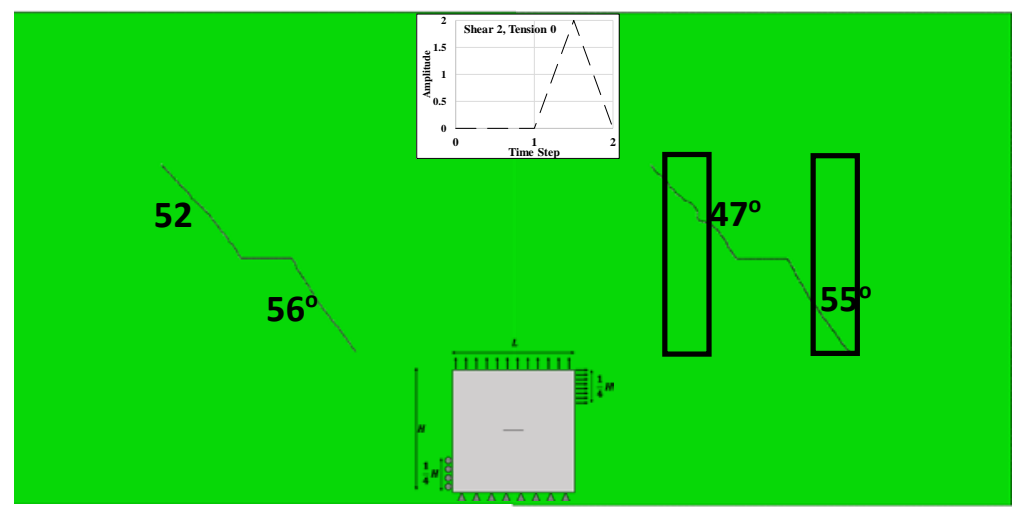

Fig. 5 Cracking patterns with and without repairs for Case 1

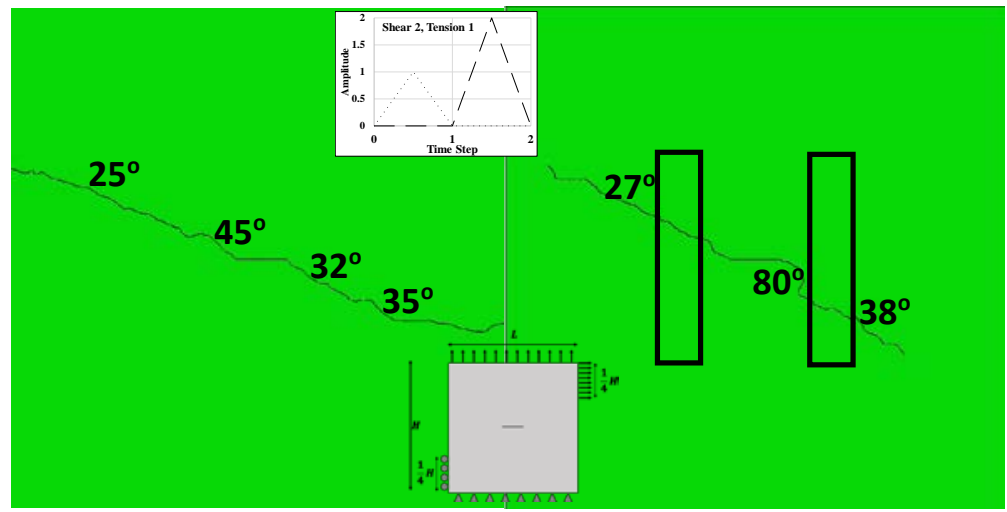

Fig. 6 Cracking patterns with and without repairs for Case 2

\subsection{Number of cycles vs half-crack length}

In order to obtain an overall clearer perspective on the effectiveness of FRP repairs under mixed-mode loading, the number of cycles vs. half crack length is shown in figure 7 for Case 1 and Case 2. The total number of cycles for both cases without repairs were 337,000 and 875,000 respectively, indicating that the pure shear case (Case 1) has less capacity to resist crack growth that the case were shear and tension are acting in the system. The mix mode loading has a 2.6 fold fatigue life increase compare to the pure shear case (Case 1). For the repaired Case 1 and Case 2 models the cycles were 755,000 and 2.1E6 respectively. For this condition, the mix mode loading repaired case (Case 2) has a $178 \%$ of fatigue life increase when compared to the repaired case subjected to only shear loading. However, when compare to the corresponding cases, the plates gain a 2.25 fold fatigue life 
increase for Case 1 and 2.40 fold fatigue life increase for Case 2. Once again, the pure shear case (Case 1) required less number of cycles to propagate the crack to an unstable length. This implies that even though the fatigue life increases are similar, the combination of tension, shear and bending presented the best load case.

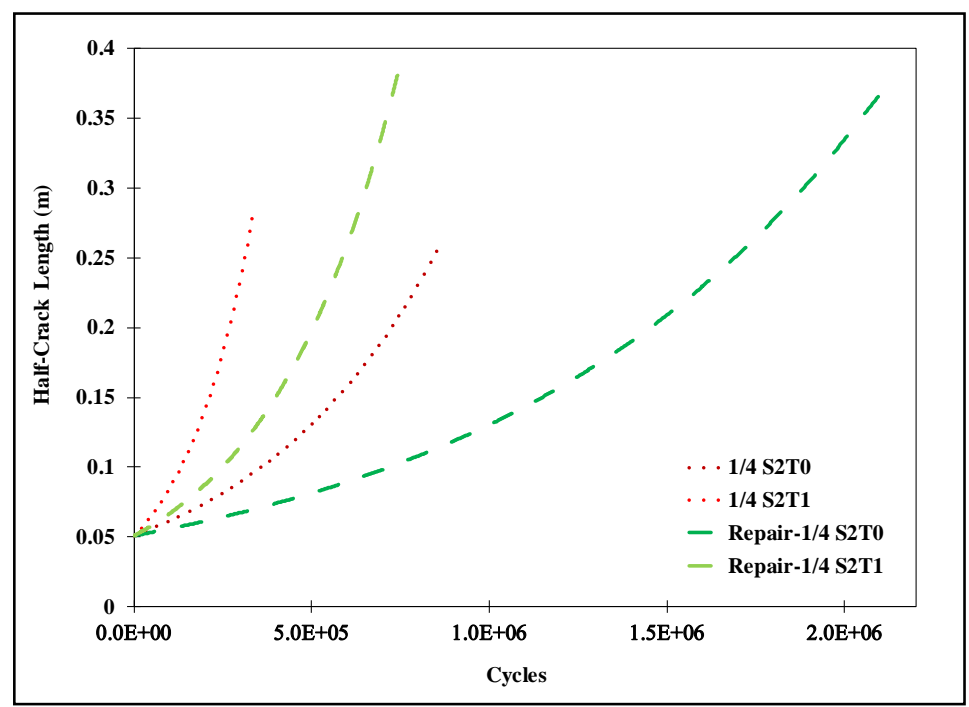

Fig. 7 Number of cycles vs half-crack length

\subsection{Principal Stresses}

Fig 8. shows the principal stresses for case 2 at three locations along the crack path for the unrepaired and repaired specimens. Location 1 is at the initial crack tip. A $16 \%$ stress reduction is provided by the CFRP patch. The second location is at the center of the CFRP patch, where a 35\% decrease of the principal stresses is achieved. Finally, location 3 is at the outside edge of the CFRP, where only a $23.7 \%$ reduction on the principal stresses is reached. Once the crack has crossed the CFRP patch, a global de-bonding begins and the benefits of the CFRP patches begins to diminish. This shows the importance of using the most ductile epoxy that allows a localized de-bonding along the crack path, reducing the potential of a fully de-bonded patch, thus allowing the CFRP strength to develop fully prior to fracture. 


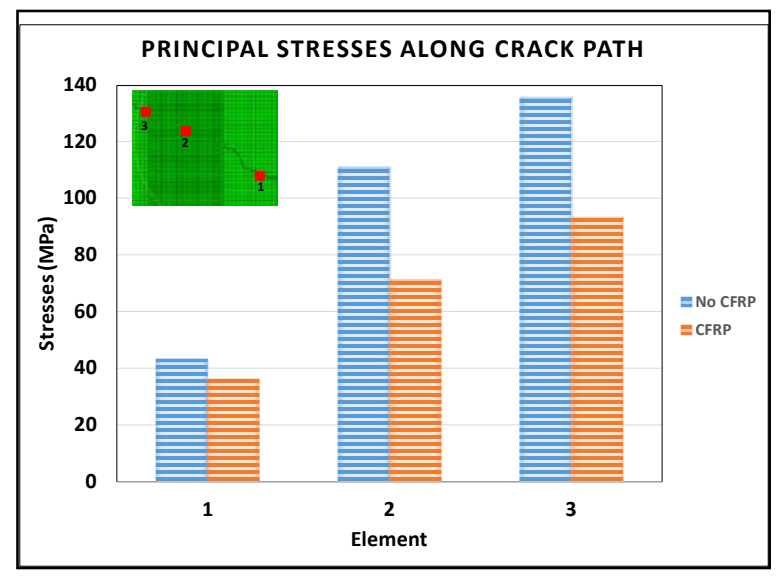

Fig. 8 Principal Stresses along crack path

\section{Conclusions}

This article presented numerical simulations to evaluate the viability of fiber reinforced polymer (FRP) retrofit methods as an alternative to repair mix-mode fatigue cracking. The numerical analysis used a combination of tension, shear, and bending forces to develop different cracking patterns. The analysis demonstrated the effectiveness of the repair techniques on the defined problem. The conclusions below are drawn from results of the numerical experiments.

- FRP reduced the principal angle for both cases, allowing the crack to grow at angles lower to those for pure shear and mix-mode loadings.

- Cases 1 and 2 showed an increase in fatigue life when repaired with unidirectional FRP by 2.25 and 2.4 times respectively.

- XFEM presents a valuable tool to evaluate mix-mode problems in navigation steel structures.

- FRP also reduces the principal angles until the cracks grow beyond the CFRP patch where global de-bonding diminished the CFRP effects.

- It is recommended that a more ductile epoxy is used to allow for localized debonding when the crack crosses the CFRP patch, allowing the CFRP strength to develop fully prior to fracture. 


\section{References}

1. B.A. Eick, Z.R. Treece, B.F. Spencer Jr., M.D. Smith, S.C. Sweeney, Q.G. Alexander, and S.D. Foltz, Miter Gate Gap Detection Using Principal Component Analysis. ERDC-TR-18-2, US Army Engineer Research and Development Center, Vicksburg, Miss, USA, 2018

2. D.V. Grier, The Declining Reliability of the US Inland waterway system, USACE 2006

3. U.S. Army Corps of Engineers (USACE). 2015. Upper Mississippi River Locks and Dams. Vicksburg, MS

4. G.A. Riveros, E. Arredondo, Prediciendo la Deterioracion de Estructuras Metalicas de Navigacion Sometidas a Cargas Hidráulicas con la Cadena de Markov y la Simulación Latin Hypercube. Rev Int Desastres Nat, Accid Infraestruct Civ 2011;11(1).

5. G.A. Riveros, E. Arredondo, K. Walker, D. Dixon, V. Fermo, J. Davis, A procedure for predicting the deterioration of steel hydraulic structures to enhance their maintenance, management, and rehabilitation. ERDC/ITL TR-14-1. Vicksburg, MS: U.S. Army Engineer Research and Development Center; 2014.

6. G.A. Riveros, M.E. Rosario, Deriving the transition probability matrix using computational mechanics. Eng Comput. 2018;35:2.

7. G.A. Riveros, J.L. Ayala-Burgos, J. Perez, (2009). "Numerical investigation of miter gates.” ERDC/ITL-TR-09-1, U.S. Army Engineer Research and Development Center (ERDC), Vicksburg, MS.

8. Headquarters, U.S. Army Corps of Engineers. Periodic inspection and continuing evaluation of completed civil works structures. Engineer regulation 1110-2-100. Washington, DC: Headquarters, U.S. Army Corps of Engineers; 1995.

9. Headquarters, U.S. Army Corps of Engineers. Reporting of evidence of distress of civil works structures. Engineer regulation 1110-2-101. Washington, DC:

Headquarters, U.S. Army Corps of Engineers; 1996.

10. A. Bassetti, P. Liechti, A. Nussbaumer, Fatigue resistance and repairs of riveted bridge members. Espoo, Finland: 3rd international symposium on fatigue design, fatigue design and reliability. 1999.

11. Federal Highway Administration. Recording and coding guide for the structure inventory and appraisal of the nation's bridges. Report no. FHWA-PD-96-001. Washington, DC: Office of Engineering, Bridge Division, Bridge Management Branch; 1995.

12. K. Maruyama, JCI Activities on Continuous Fibre Reinforced Concrete, Non-Metallic (FRP) Reinforcement for Concrete Structures. J. C. Institute: 3-12 (1997).

13. K. Neale, P. Labossiere, State-of-the-art Report on Retrofitting and Strengthening by Continuous Fibre in Canada. J. C. Institute: 25-39 (1997).

14. J. Thomas, FRP Strengthening - Experimental or Mainstream Technology? Concrete International: 57-58 (1998).

15. T.C. Triantafillou, Shear Strengthening of Reinforced Concrete Beams Using Epoxy Bonded FRP Composites. ACI Structural Journal 95(2): 107-115(1998).

16. A. Hosseini, E. Ghafoori, M. Motavalli, A. Nussbaumer, X. Zhao, Mode I fatigue crack arrest in tensile steel members using prestressed CFRP plates. Compos Struct;178:119-34 (2017). 
17. P. Colombi, A. Bassetti, A. Nussbaumer, Crack growth induced delamination on steel members reinforced by prestressed composite patch. Fatigue Fract Eng Mater Struct;26(5):429-37 (2003).

18. ABAQUS v6.14. Dassault systems, Providence, RI; 2014.<www.simulia.com>.

19. G.A. Riveros, H. Mahmoud, C. Lozano, Fatigue Repair of Underwater Navigation Steel Structures using CFRP, Elsevier Engineering Structures, Vol 173, Pages 718728 (2018).

20. H.N. Mahmoud, G.A. Riveros, M. Memari, A.j Valsangkar, Underwater Large-Scale Experimental Fatigue Assessment of CFRP-Retrofitted Steel Panels, ASCE Journal of Structural Engineering, 144(10): 04018183 (2018).

21. P. Paris, M. Gomez, W. Anderson, A rational analytic theory of fatigue. Trends Eng. 13, 9-14 (1961).

22. P. C. Paris, H. Tada, J.K. Donald, Service load fatigue damage-a historical perspective, Int. J. Faigue 21, S35-S46 (1999). 